\title{
e-HEALTH AND CARE SERVICE INTEGRATION: THE DEMOGRAPHIC CHALLENGE
}

\author{
Bryan.R.M. Manning and Mary.McKeon Stosuy \\ Centre for Business Information, Organisation, and Process Management, \\ Westminster Business School, University of Westminster, UK \\ Bryan.Manning@btintemet.com \\ Marv.McKeon@dolo.state.rit.us
}

\begin{abstract}
The imbalance between demand and available resources, based on the forecast doubling of over 65 s to about $40 \%$ of the populations of many nations will force radical changes in health and social care service delivery in the coming decades.

The creation of "Virtual Care Service Utilities" to coordinate and optimize use of scarce resources coupled with the extensive use of assistive technology systems is examined. The potential benefits are reviewed and weighed against the inherent loss of privacy involved, together with the trust building and change management implications of such a major rationalisation process.
\end{abstract}

\section{INTRODUCTION - THE DEMOGRAPHIC IMPERATIVE}

Governments across much of the developed world are faced with having to respond to growing impacts of an ageing population as forecasts all show a steep rise in the percentage of the population who are older than 65 years doubling to close to $40 \%$ by the middle of the century.

Even from these crude estimates it is evident that current models of care are wholly unsustainable on human resource grounds alone, since lowering birthrates will tend to reduce the available numbers of professionals, whilst demand for their services soar. Moreover expectations of evermore sophisticated, live-span extending treatments have taken hold and will undoubtedly increase this pressure for political action from the swelling numbers of voters concerned.

Whilst the most obvious response will of necessity be to try to get more out of the available system, there is an increased recognition that the traditional model based on multiple service providers operating mainly in informal collaboration with each other is hardly efficient. As a result the quality of care is far from optimal and all too easily results in repetitive and often unnecessary returns back into the care cycle, further increasing demand.

\section{LOCUS OF CARE}

This issue exemplifies the interlocking nature of effective care delivery, outlined in Figure 1, which the traditional 'silo' organisational approach to service provision misses. Over the past few years this interlinking dependency between medical and social care has begun to be recognised and responded to. 


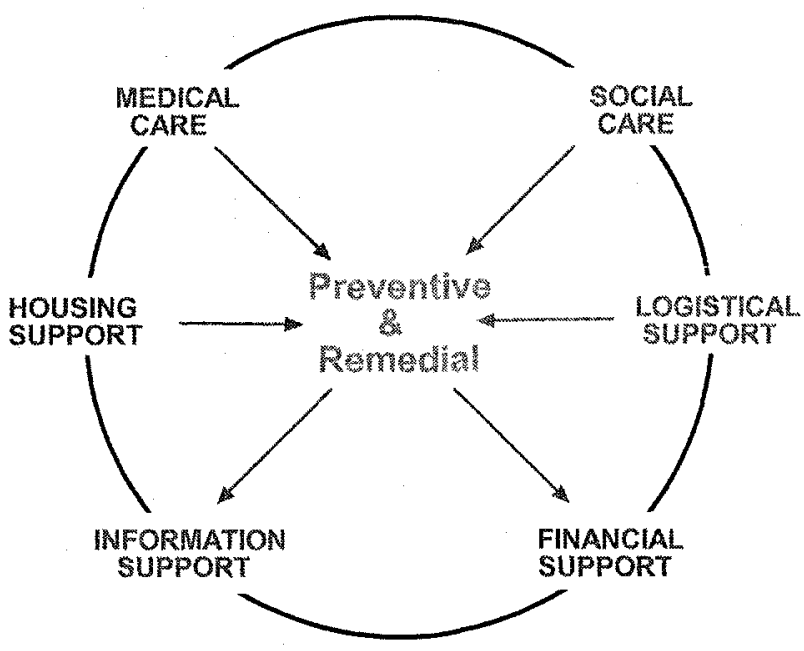

Figure.1 - Components in the Locus of Care

However the further dependencies on adequacy of housing in terms of cost, warmth, hygiene and security, together with that of personal logistics needed to obtain food and other basics necessities of life remain largely ignored and disconnected.

Similarly personal finance can be added to this list of disconnects, especially for the elderly who are frequently capital rich - through home ownership, yet revenue poor for many reasons, including lack of understanding of available benefits.

Finally whilst access to useful information across this spectrum of need is increasing, and its content of considerable potential use, its quality and coverage can be highly variable. Although Information and Communications Technology [ICT] has provided the enabling mechanism for all this, its ubiquitous nature has also logically expanded its boundaries to incorporate a wide range of diversified sensor based systems that are steadily becoming an unnoticed element in daily life.

Now recognized as Pervasive Computing, this plays a key role in the development of evermore sophisticated Assistive Technology designed to support the elderly at home.

\section{OPTIONS FOR CHANGE}

Whilst some further improvement can undoubtedly be wrung out of the existing multi-agency approach, the very scale of the problem indicates that a more radical solution will be required. In the circumstances the only really available option will be to restructure services by removing these boundaries and barriers and optimizing complete end-to-end care delivery processes within a 'virtual service utility'.

Although this has the potential to deliver considerable operational improvement, it is unlikely that this alone will stem the effect of spiraling demand and a diminishing resource pool. The best option to combat this will be to compensate for 
excessive workload imbalances by substituting Assistive Technology [AT] wherever practical and appropriate, as shown in Figure 2.

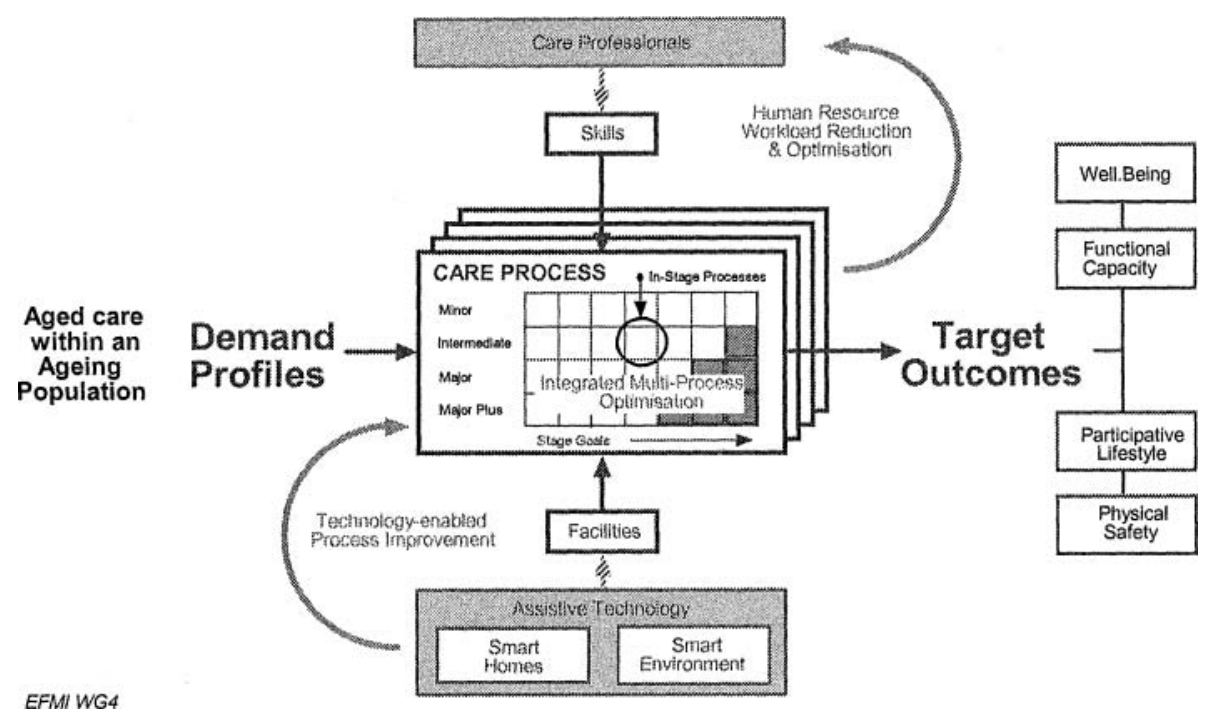

Figure 2 - Enabling Care Process Optimisation

Much of this can come from the deployment of systems to provide powerful proactive lifestyle support, as well as monitoring clinical conditions and behavioural patterns to identify and respond to any serious abnormal circumstances. These will preclude many an unnecessary home visit, whilst safeguarding and reassuring the individuals concerned that they have continuous cover with care readily at hand when needed.

This approach takes forward the concepts of the "Virtual Hospital" and combines them with a similar approach to providing more effective "Care in the Community". By providing a combination of medical and personal welfare monitoring through a "Care Watch" service, the level of care support will be similar to that available in a hospital high dependency unit. The obvious difference is that the response will need to be provided by existing paramedic services, extended to include additional "parawelfare" capabilities.

Its overall aim is to enable those suffering from increasing levels of impairment to continue to maintain an independent and participative lifestyle in the community for as long as possible.

\section{OPTIONS FOR CHANGE}

Whilst many ways to restructure and rationalize services will undoubtedly emerge to form an integrated service, the more likely model is that of a 'virtual service utility' rather than that of a monolithic entity. For optimum effectiveness it is likely to need to focus on fairly localized service provision to support communities rather than purely administrative convenience. However in the interests of good governance this 
will need to be set within an appropriate legislative and regulatory framework set to ensure maintenance of high quality services and standards, shown in Figure 3.

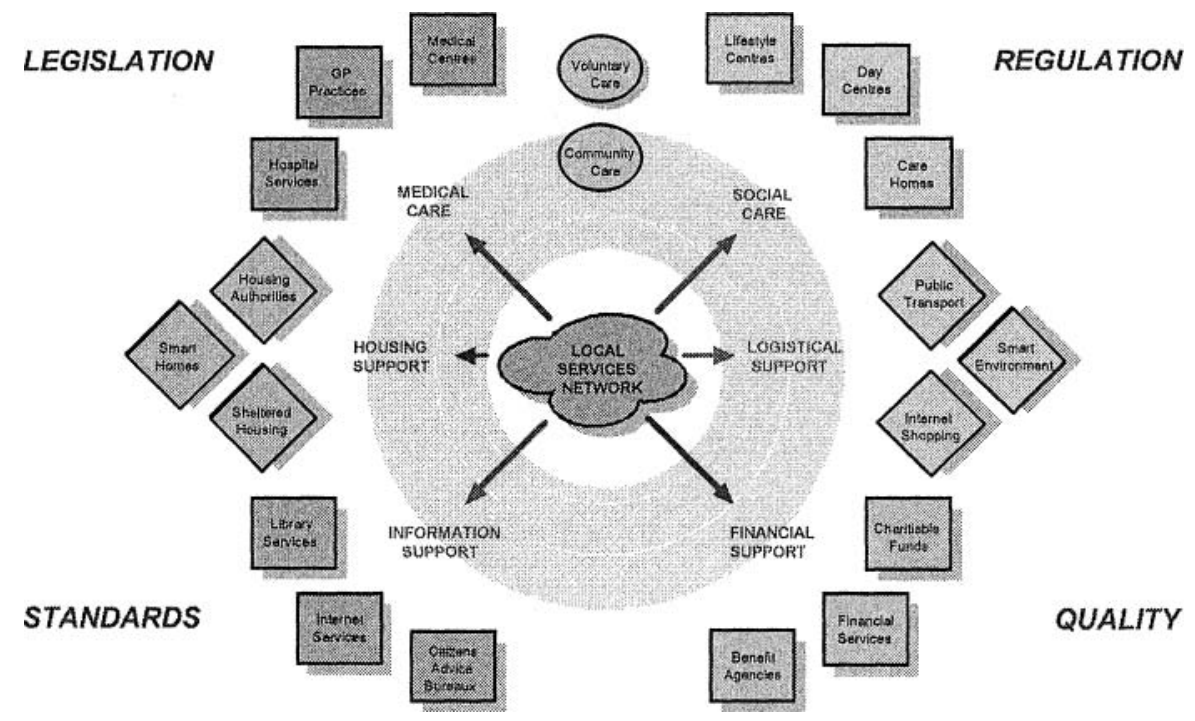

Figure 3 - Care Service Utility Elements

In essence the 'virtual service utility' will bring together the main strands identified within the locus of care and extend them out into the many individual units and specialist providers that deliver services across the complete spectrum of need. This will allow reconfiguration of local teams to maximum effect whilst still maintaining flexibility and relative autonomy.

The key to this will be the preparedness for all concerned to coordinate their efforts through one or more 'care watch' centers, which will be responsible for initiating appropriate responses to need of all types within the communities they serve.

\section{5. e-CARE AND ASSISTED LIFESTYLES}

The role of e-Care within the 'virtual service utility' is to combine coordination of human resources with those of semi or fully autonomous Assistive Technology [AT] systems to enable users to maintain their independence. As these AT systems can include physiological and behavioural monitoring they can be set to detect abnormal patterns and initiate appropriate care service responses.

All care cycles commence with a formal Assessment of Need. This is used to set up a Care Plan for planned and emergency professional support interventions. In this scenario this would also include Support System planning for the deployment of AT, as shown in Figure 4. 


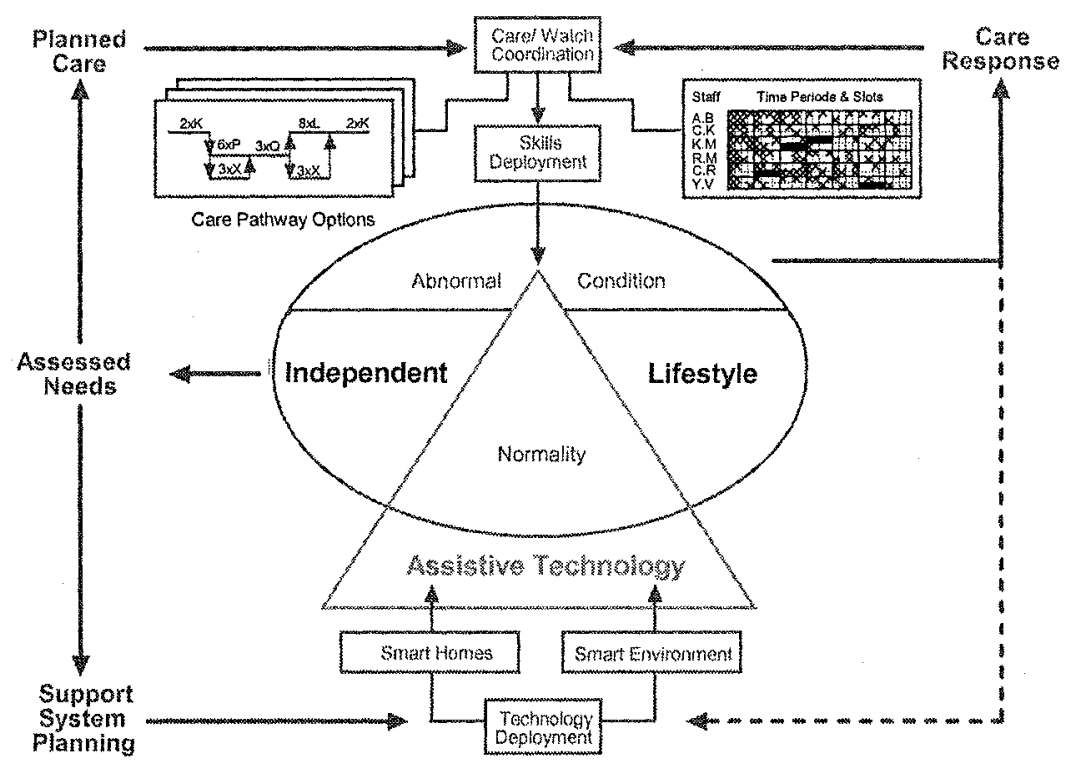

Figure 4 - Integrated e-Care Model Paradigm

Whilst professional care practice would broadly remain the same, the aim would be to use shared Integrated Care Pathway planning to eliminate the current wasteful tendency not to recognise key interdependencies between disciplines and/or agencies' procedures.

Service coordination and operational back-up would be provided via a shared Care Watch centre, which would be able to initiate action in response to any abnormal event/condition indications.

\section{6. e-CARE WATCH COORDINATION}

Although Care Watch coordination is essentially a back office function it can easily be combined with current "one-stop-shop" Resource Center practice as a single entity, since there is a considerable overlap in both functionality and skill requirements. Whilst the Resource Center approach is generally designed to cover matters across the complete locus of care service provision either through 'face-toface' contact or by phone/e-mail, Care Watch extends the call centre component to include a monitoring and response function.

Rationalisation of multi-disciplinary multi-agency services into a "virtual utility service" operation does not require massive corporate restructuring, but does entail the merging of information resources within a mutually trusting environment. It also enables the pooling of administrative and management resources; the recognition of interdependencies between processes in the service supply chain and its resultant shortening; and more effective and appropriate deployment of resources, as shown in Figure 5. 


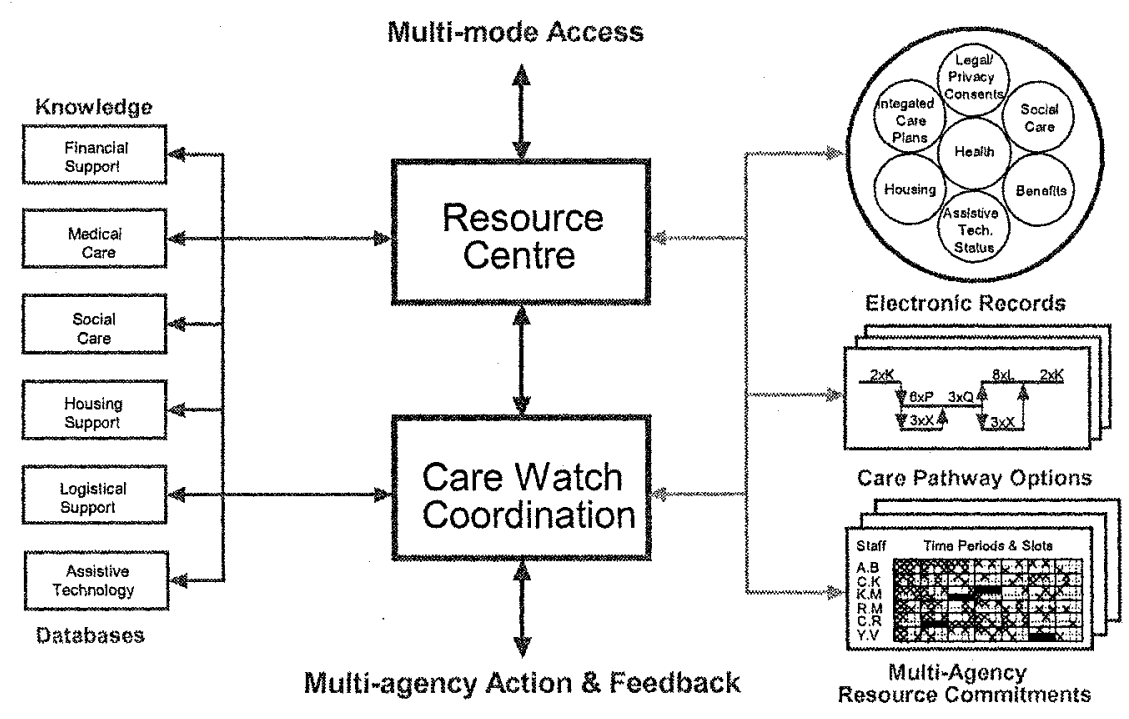

$$
\begin{gathered}
\text { Care Process } \\
\text { Monitoring } \\
\text { Auto Responses }
\end{gathered}
$$

Figure 5 - An Integrated Care Service Model

Secure e-business information services within these 'hubs' would comprise shared:

- Multi-agency electronic client/patient records

- Multi-disciplinary Care Pathway Option maps

- Multi-agency, multi-disciplinary Resource Commitment schedules

- A library of knowledge databases spanning each of the elements of the overall the locus of care.

- A dedicated $24 / 7$ manned Care Watch monitoring and response coordination unit

As currency and accuracy of information from all sources will be vital to ensuring that correct action is taken or right advice and guidance is given, the underlying information systems will need to be maintained and validated in realtime.

\section{ASSISTIVE TECHNOLOGY}

Assistive Technology has been evolving for several decades under a number of guises that have tended to be reserved for rehabilitation and disability. Indeed impairment and disability have long been somewhat of a clinical backwater and even an area that is almost alien to the rest of medicine. Disability thus sits uncomfortably between health and social care, impinging on both but set apart from each of them. 
This apparent disadvantage has instead been turned to good effect through unfettered relationships across the whole range of professions involved with providing goods and services to the public. Considerable advances have been made in the development of the Smart Home and Smart Community concepts using sophisticated wired and wireless communications and computing systems ${ }^{5}$ in conjunction with innovative ergonomic product and built-environmental design

The Smart systems approach is based on an internet infrastructure communicating via an appropriate gateway either from individual devices or a local area network set within individual homes. These devices range in sophistication from alarms triggered by a range of safety and security condition monitoring sensors through to clinical vital signs monitoring arrays embedded with wearable vests.

With funding support from the European Commission COST 219 set of programmes, the Scandanavian and Benelux countries have led the way in proving these principles through a number of practical pilot projects spanning whole communities. These are not necessarily confined to features for the disabled but include improved ergonomic support for activities of daily living though a variety of interactive systems.

\section{PRIVACY}

Whilst there are undoubted benefits to be gained in terms of the independent, safe and secure lifestyle that Assistive Technology can help deliver, it carries with it disturbing overtones of unwarranted 'Big Brother' invasion of privacy. However despite these obvious and reasonable concerns, both a solution and a precedent already exist in medicine in terms of the Consent for Clinical Intervention procedures. These control the conditions and permissions under which medical staff are allowed to 'invade' their patients body to carry out investigative and therapeutic procedures.

In essence the same form control process could be applied to regulate invasion of the personal space and privacy of any individual.

As with all care decisions privacy rights like all others have to be weighed against the benefits that are likely to accrue, whilst protected against abuse by appropriate legal constraints. The ongoing concern of all parties engaged with the development and application of pervasive computing must be to build-in protection at all levels against unreasonable and unlawful misuse of unpredictable and largely invisible systems and their evolution.

\section{CONCLUSIONS}

The undoubted problems that the demographic challenge of the predicted growth in the numbers of elderly will present nations and their governments are already beginning to surface. However, whilst it has been argued here that technology has the potential to provide the means to deliver a solution, it is far from being the solution in itself.

Indeed this trap has been fallen into with monotonous regularity, particularly where Information Technology has been concerned. Sadly there have been 
innumerable, well documented failures, where high hopes and expectations have been dashed on the rocks of massive delays, cost overruns and fundamental failures to deliver systems that actually function effectively in the real world.

Unfortunately real tools, however well crafted, have to be used in an imperfect and ever changing human environment that has an infuriating tendency to reject what "ought" to be good or at least useful to, or for it. This is especially true where professions and professional judgement are central to service delivery and is particularly so in medicine.

In these circumstances it is vital to understand the nuances of the professional working cultures and work within them to help develop practical, pragmatic solutions to problems that regularly beset them and they would dearly like to have the time to solve. Framework models that map the gist of these problems in ways that these professionals can identify with and then help them find a solution that they own from the outset have proved far more likely to succeed, than force-feeding them a technically evaluated prescription for a complaint that they do not have.

\section{REFERENCES}

1. Acts of Parliament: The Human Rights Act 1998, Chapter 42, 1998

2. Benton S, Manning B.R.M. Assistive Technology - Behaviourally Assisted. Proceedings $-3^{\text {rd }}$ International Council of Medical and Care Compunetics Conference. Den Haag, Netherlands. June 2006

3. Cameron I. The Information Society: Emerging Landscapes, Proceedings of the IFIP WG 9.2 Conference on Landscapes of ICT and Social Accountability. Turku, Finland, 27-29 June 2005. Springer Publishers, USA. 2005

4. Cas J. Privacy in Pervasive Computing Environments. IEEE Technology and Society Magazine Spring 2005. 24-33. 2005

5. Commission of the European Communities [COM(2001) 723 Final]: The future of healthcare and care for the elderly: guaranteeing accessibility, quality and financial viability. 5/12/2001

6. Commission of the European Communities [COM(2004) 356]: e-Health - making healthcare better for European citizens: An action plan for a European e-Health Area. 2004

7. Gill J. [Ed.]. Making Life Easier. COST 219. 2005.

8. Manning B.R.M, Stosuy M. McKeon, Layzell B.R, Madani K. e-Care: An Assistive Technology enabled Paradigm Shift. Proceedings - 4th International Conference On Smart Homes and Health

9. Office of the Deputy Prime Minister: A Sure Start to Later Life: Ending Inequalities for Older People A Social Exclusion Unit Final Report. London, January 2006

10. Office of the Deputy Prime Minister: Inclusion Through Innovation Tackling Social Exclusion Through New Technologies - A Social Exclusion Unit Final Report

11. Roe P.R.W. (Ed.), Bridging the Gap? Access to telecommunciations for all people. Commission of European Communities. Presses Centrales Lausanne SA, November.2001

12. Parliamentary Office of Science and Technology. Inquiry Findings on Pervasive Computing, February 2006

13. Steg H, Strese H, Hull J, Schmidt S. Europe is facing a demographic chanlenge Ambient Assisted Living offers solutions, VDI/VDE/IT, September 2005

14. Stosuy G.A, Eaglin J.P. The Community Services Network: Creating an integrated Service Delivery Network - The Baltimore open systems laboratory model. New Technology in the Human Services Vol 12 1/2 87-98. NTHS 1999

15. Stosuy M.McKeon, Manning B.R.M. "Joining Up" e-Health \& e-Care Services: Meeting the Demographic Challenge, Proceedings $-2^{\text {nd }}$ International Council of Medical and Care Compunetics Conference. Den Haag, Netherlands. June 2005

16. Zetuny $\mathrm{Y}$, Kecskemeti $\mathrm{G}$, Terstyansky $\mathrm{G}$, Madani $\mathrm{K}$, "Service Management Architecture in ePerSpace", Eurescom Summit 2005, Heidelberg, 27/04/05. 